\title{
Plasmodium malariae
}

National Cancer Institute

\section{Source}

National Cancer Institute. Plasmodium malariae. NCI Thesaurus. Code C123548.

A protozoan parasite in the family Plasmodiidae. P. malariae causes quartan malaria, a

milder form of malaria than that caused by $P$. falciparum or P. vivax. 